\title{
Inhibition of autophagy enhances adenosine-induced apoptosis in human hepatoblastoma HepG2 cells
}

\author{
XIAO-TAO ZHOU ${ }^{1 *}$, ZE-JIN PU $^{1 *}$, LI-XUAN LIU ${ }^{1}$, GUO-PING LI ${ }^{1}$, \\ JIA-LIN FENG ${ }^{2}$, HUA-CHEN ZHU ${ }^{3}$ and LING-FEI WU ${ }^{1}$
}

\author{
Departments of ${ }^{1}$ Gastroenterology and ${ }^{2}$ Information, The Second Affiliated Hospital, \\ Shantou University Medical College; ${ }^{3}$ State Key Laboratory of Emerging Infectious Diseases, \\ Shantou University-The University of Hong Kong Joint Institute of Virology, \\ Shantou, Guangdong 515041, P.R. China
}

Received June 27, 2018; Accepted November 12, 2018

DOI: $10.3892 / o r .2018 .6899$

\begin{abstract}
In cancer research, autophagy acts as a double-edged sword: It increases cell viability or induces cell apoptosis depending upon the cell context and functional status. Recent studies have shown that adenosine (Ado) has cytotoxic effects in many tumors. However, the role of autophagy in Ado-induced apoptosis is still poorly understood. In the present study, Ado-induced apoptotic death and autophagy in hepatoblastoma HepG2 cells was investigated and the relationship between autophagy and apoptosis was identified. In the present study, it was demonstrated that Ado inhibited HepG2 cell growth in a time- and concentration-dependent manner and activated endoplasmic reticulum (ER) stress, as indicated by G0/G1 cell cycle arrest, the increased mRNA and protein levels of GRP78/BiP, PERK, ATF4, CHOP, cleaved caspase-3, cytochrome $c$ and the loss of mitochondrial membrane potential $(\Delta \Psi \mathrm{m})$. Ado also induced autophagic flux, revealed by the increased expression of the autophagy marker microtubule-associated protein 1 light chain 3-II (LC3-II), Beclin-1, autophagosomes, and the degradation of p62, as revealed by western blot analysis and macrophage-derived chemokine (MDC) staining. Blocking autophagy using LY294002 notably entrenched Ado-induced growth inhibition and cell apoptosis, as demonstrated with the increased expression of cytochrome $c$ and $\mathrm{p} 62$, and the decreased expression of LC3-II. Conversely, the autophagy inducer rapamycin alleviated Ado-induced apoptosis and markedly increased the $\Delta \Psi \mathrm{m}$. Moreover, knockdown of AMPK with
\end{abstract}

Correspondence to: Professor Ling-Fei Wu, Department of Gastroenterology, The Second Affiliated Hospital, Shantou University Medical College, 69 Dongxia Road, Shantou, Guangdong 515041, P.R. China

E-mail: lingfeiwu@21cn.com

*Contributed equally

Key words: adenosine, autophagy, apoptosis, endoplasmic reticulum stress, AMPK/mTOR/ULK1, hepatoblastoma HepG2 cells
si-AMPK partially abolished Ado-induced ULK1 activation and mTOR inhibition, and thus reinforced CHOP expression and Ado-induced apoptosis. These results indicated that Ado-induced ER stress resulted in apoptosis and autophagy concurrently. The AMPK/mTOR/ULK1 signaling pathway played a protective role in the apoptotic procession. Inhibition of autophagy may effectively enhance the anticancer effect of Ado in human hepatoblastoma HepG2 cells.

\section{Introduction}

Liver cancer is the most common type of cancer and the third leading cause of cancer-related deaths worldwide due to its poor prognosis (1). Treatment of liver cancer includes surgery, intervention therapy, chemotherapy and liver transplantation, however the therapeutic effect is not satisfactory. As a non-invasive treatment, chemotherapy is still a major method for advanced tumor at present. However, no systemic chemotherapy has been demonstrated to be consistently efficacious and acquisition of drug-resistant phenotypes is often associated with liver cancer chemotherapy. Reducing the drug resistance of chemotherapy is a major clinical problem (2).

Escape from chemotherapy is positively correlated with the unfolded protein response (UPR) and autophagy (3-5). Autophagy plays a significant role in energy homeostasis by degradation and recycling of damaged or harmful intracellular components. Overload of misfolded or unfolded proteins in the endoplasmic reticulum (ER) leads to a failure of protein degradation by proteasomes, causing the upregulation of autophagy (6-8). It has been revealed that autophagy may function as a cytoprotective mechanism, since the signaling pathways of intrinsic and extrinsic apoptosis are blocked after autophagy activation and result in adaptation and survival of tumor cells under hypoxic and inflammatory conditions (9-11). In addition, an increasing number of studies have revealed that autophagy may also contribute to resistance to chemotherapy for cancer (12-14). Although autophagy is a potential therapeutic target in adjuvant chemotherapy, its exact role is still unclear.

Adenosine (Ado) is an endogenous purine nucleoside composed of an adenine attached to a ribose sugar molecule 
moiety, and is present ubiquitously in all the organs, tissues and cells. Accumulating evidence has revealed that Ado induces apoptosis in a variety of cancer cells (15-17). ER stress and the mitochondrial pathway may be involved in the Ado-induced apoptosis process (18-20). Cellular adaptation to ER stress is achieved by the activation of a highly conserved signal transduction pathway known as the UPR, which alleviates stress at an early stage and triggers apoptosis if homeostasis fails over a prolonged time frame. UPR involves an ER molecular chaperone (GRP78), ER stress sensor proteins (PERK, IRE-1 and ATF-6) and their downstream signaling pathways (21). During ER stress, PERK dissociates from GRP78 and activates ATF4, which promotes transcription of genes related to cell survival and pro-apoptotic factors such as CHOP. CHOP can alter the permeability of the mitochondrial membrane and lead to the subsequent release of pro-apoptotic molecules cytochrome $c$ (Cyt C), which further activates caspases to promote cell apoptosis (22). In our previous studies, we demonstrated that Ado-induced apoptosis was associated with activation of ER stress $(19,23)$. However, whether Ado affects autophagy, or whether autophagy plays a protective role on cells is unclear. Therefore, it is necessary to further investigate the relationship between autophagy and apoptosis.

\section{Materials and methods}

Cell culture and experimental groups. The human hepatoblastoma HepG2 cell line (Institute of Cell Biology at the Chinese Academy of Sciences, Shanghai, China) were cultured in Dulbecco's modified Eagle's medium (DMEM) containing $10 \%(\mathrm{v} / \mathrm{v})$ fetal bovine serum, penicillin (final concentration, $100 \mathrm{U} / \mathrm{ml}$ ), and streptomycin (final concentration, $100 \mu \mathrm{g} / \mathrm{ml}$ ) (all from Thermo Fisher Scientific, Inc., Waltham, MA, USA), under a humidified atmosphere of $5 \% \mathrm{CO}_{2}$ and $95 \%$ air at $37^{\circ} \mathrm{C}$. This growth medium was changed every two or three days, and cells were passaged at $\sim 80 \%$ confluence. To validate that autophagy participates in Ado-induced apoptosis, the autophagy inhibitor LY294002 (LY; Calbiochem, San Diego, CA, USA) and the autophagy inducer rapamycin (Rapa) were pre-treated and $1 \%$ dimethyl sulfoxide (DMSO) was used as a control (Control).

Transient transfection. For RNAi experiments, the plasmid encoding a small interference RNA (siRNA) targeted against AMP-activated protein kinase (AMPK) (si-AMPK) or an empty plasmid vector only expressing GFP (control siRNA) was constructed. We first constructed four si-AMPK sequences and these interference plasmids were named si-AMPK1, si-AMPK-2, si-AMPK-3 and si-AMPK-4, respectively. The plasmid which had the highest inhibition efficiency (78\%) was selected for the next experiments (data not shown). The best sequence of si-AMPK, 5'-CUGAGUUGCAUAUACUGUA-3' and control-siRNA, 5'-GACGAGCGGCACGUGCACA-3' were synthesized by GenePharma Co., Ltd. (Shanghai, China). For transfection, cells were trypsinized and seeded in 6-well plates at a density of $4 \times 10^{5}$ cells/well. Two days after reaching confluence, HepG 2 cells were cultured in a serum-free medium for $1 \mathrm{~h}$ and transfected with $20 \mu \mathrm{M}$ of the target gene or control siRNA using Lipofectamine 2000 (Thermo Fisher Scientific, Inc.) according to a method described in our previous study (19).
Following a change of fresh medium $6 \mathrm{~h}$ later, the transfected cells were incubated with or without $2.0 \mathrm{mM}$ Ado in complete medium for a further $24 \mathrm{~h}$, then the cells were collected and named: Adenosine treatment group (Ado), Ado+si-AMPK or control siRNA group. These transfected cells were processed for western blot analysis and measurement of mitochondrial membrane potential.

MTT assay to detect the cell viability. HepG2 cells were seeded in a 96-well plate $\left(5 \times 10^{3}\right.$ cells/well $)$ in a humidified atmosphere with $5 \% \mathrm{CO}_{2}$ at $37^{\circ} \mathrm{C}$ and treated with Ado alone $(0,1.0,2.0,3.0$ and $4.0 \mathrm{mM})$ for 12,24 and $48 \mathrm{~h}$; or $2.0 \mathrm{mM}$ Ado alone, $10 \mu \mathrm{M} \mathrm{LY}$ alone or $2.0 \mathrm{mM}$ Ado in combination with $10 \mu \mathrm{M}$ LY for 12, 24, 36 and $48 \mathrm{~h}$. Subsequently, $10 \mu \mathrm{l}$ MTT $(5 \mathrm{mg} / \mathrm{ml})$ was added to each well and cells were incubated for an additional $4 \mathrm{~h}$. Following removal of the supernatant, DMSO (100 $\mu \mathrm{l} /$ well) was added to dissolve the blue formazan crystals converted from MTT by HepG2 cells. Cell viability was assessed using a microplate reader at an optical density of 560 nm (Wellscan K3; KHB Labsystems, Helsinki, Finland). The experiment was repeated three times.

Cell cycle analysis. HepG2 cells were seeded in a 96-well culture plate and incubated with $2.0 \mathrm{mM}$ Ado at $37^{\circ} \mathrm{C}$ for different time-points $(6,12$ and $24 \mathrm{~h})$. Cells were collected after trypsin treatment, washed with phosphate-buffered saline (PBS), and then cell pellets were resuspended in $1 \mathrm{ml}$ of $50 \mu \mathrm{g} / \mathrm{ml}$ solution of propidium iodide (PI) in buffer, and incubated in the dark at room temperature for $15 \mathrm{~min}$. The PI fluorescence was assessed on a FACScan flow cytometer (FACSCalibur; BD Biosciences, San Jose, CA, USA) and the cell cycle distribution was analyzed using ModFit 3.2 software (Verity Software House, Inc., Topsham, ME, USA).

Hoechst staining and observation of nuclear structure. HepG2 cells were seeded in a 96-well plate with $3 \times 10^{3}$ cells/wellovernight, and then incubated with Ado alone, Ado + Rapa or Ado + LY respectively for an additional $12 \mathrm{~h}$. Then the cells were washed with PBS and stained by adding $0.5 \mathrm{ml} /$ well Hoechst 33258(10 mg/l) (Sigma-Aldrich; Merck KGaA, Darmstadt, Germany) followed by washing in PBS. Condensed or fragmented nuclei, characteristic of apoptotic cells, were assessed by fluorescence microscopy. The fraction of apoptotic cells was calculated as the number of apoptotic cells divided by the number of total cells. Apoptosis scores were determined, from five randomly selected fields, by counting 500 cells directly in each sample using a blinded method.

Fluorescence microscope and flow cytometric analysis of apoptosis. Apoptotic cells were quantified with an Annexin V and PI detection kit (Nanjing KeyGen Biotechnology Co., Ltd., Nanjing, China), and by flow cytometric analysis. Briefly, cells were treated with $2.0 \mathrm{mM}$ Ado for $24 \mathrm{~h}$, washed twice with PBS, resuspended in $1 \mathrm{ml}$ of binding buffer, stained for $15 \mathrm{~min}$ at room temperature with Annexin V and PI, and sorted on a FACSCalibur instrument with CellQuest software (BD Biosciences).

MDC staining and observation of autophagy. HepG2 cells in 24-well plates were treated with or without Ado for 
$24 \mathrm{~h}$. Subsequently, the cells were incubated with $50 \mu \mathrm{mol} / 1$ monodansylcadaverine (MDC) (Sigma-Aldrich; Merck KGaA) in medium at $37^{\circ} \mathrm{C}$ for $1 \mathrm{~h}$. The cells were then fixed with $4 \%$ paraformaldehyde for $15 \mathrm{~min}$. Subsequent to rinsing twice with cold PBS and photographed by fluorescence photometry.

Protein extraction and western blotting. Western blot analysis was performed as previously described (19). Briefly, protein $(50 \mu \mathrm{g})$ was subjected to electrophoresis on $12.5 \%$ SDS-PAGE and then transferred onto nitrocellulose membranes. The membranes were blocked with $5 \%$ non-fat dry milk in Tris-buffered saline containing $0.5 \%$ Tween-20 at room temperature for $60 \mathrm{~min}$. Then the transferred membranes were incubated with primary antibodies in TBS at $4^{\circ} \mathrm{C}$ overnight. The primary antibodies LC3-I/II (D3U4C; cat. no. 12741), Beclin-1 (D40C5; cat. no. 3495), p62 (D5E2; cat. no. 8025), cleaved caspase-3 (Asp175; cat. no. 8025) were obtained from Cell Signaling Technology, Inc. (Beverly, MA, USA). ATF4 (cat. no. ab23760), GRP78 (cat. no. ab21685), PERK (cat. no. ab65142), p-AMPK (cat. no. ab133448), AMPK (cat. no. ab80039), p-ULK1 (cat. no. ab229540), ULK1 (cat. no. ab167139), p-mTOR (cat. no. ab84400), mTOR (cat. no. ab32028), CHOP (cat. no. ab11419), cytochrome $c$ (cat. no. ab110325) and $\beta$-actin (cat. no. ab8226) were purchased from Abcam (Cambridge, MA, USA). The dilution of all primary antibodies was 1:1,000. After washing with Tris-buffered saline with Tween-20 (TBST3) times for $8 \mathrm{~min}$, the membranes were incubated with peroxidase-conjugated secondary antibodies (goat anti-mouse IgG, A32723 or goat anti-rabbit IgG; A32732; both 1:5,000, Invitrogen; Thermo Fisher Scientific, Inc.) for $1 \mathrm{~h}$ at room temperature. Bands were visualized with an ECL detection system (Thermo Fisher Scientific, Inc.). Protein expression was analyzed by the Quantity One software (National Institutes of Health, Bethesda, MD, USA) and normalized to that of $\beta$-actin. In addition, a cell Mitochondria Isolation kit (Beyotime Institute of Biotechnology, Jiangsu, China) was used to extract proteins in mitochondria in order to analyze cytochrome $c$.

$R N A$ preparation and reverse transcription-quantitative polymerasechain reaction ( $R T-q P C R$ ) assay. TotalRNA was extracted from cells using the total RNA kit (Thermo Fisher Scientific,Inc.) and cDNAs were synthesized using a Revert Aid First Strand cDNA Synthesis kit (Fermentas; Thermo Fisher Scientific, Inc.) in accordance with the manufacturer's instructions. The primer sequences used for RT-PCR analysis are listed in Table I. Real-time RT-PCR was performed with an ABI PRISM 7900 Sequence Detection System (Applied Biosystems, Inc., Foster City, CA, USA) using SYBR-Green PCR Master Mix (Roche Diagnostics GmbH, Mannheim, Germany). The thermal cycling conditions were as follows: $95^{\circ} \mathrm{C}$ for $10 \mathrm{~min} ; 95^{\circ} \mathrm{C}$ for $15 \mathrm{sec}$, and then $58^{\circ} \mathrm{C}$ for $30 \mathrm{sec}$ for 40 cycles. All reactions were run in triplicate. Amplified samples were subjected to agarose electrophoresis with ethidium bromide as the fluorescent dye. Analysis of the relative gene expression data was performed by the $2^{-\Delta \Delta \mathrm{Cq}}$ method (24).

Measurement of mitochondrial membrane potential $\left(\Delta \Psi_{m}\right)$. HepG 2 cells were seeded at $4 \times 10^{5}$ cells/well into 6-well plates. After $24 \mathrm{~h}$ of incubation, the cells were incubated Ado, LY or
Table I. Primer sequences for RT-PCR.

\begin{tabular}{|c|c|}
\hline Genes & Sequence \\
\hline $18 \mathrm{~s}$ & $\begin{array}{l}\text { F: 5'-AAACGGCTACCACATCCAAG-3' } \\
\text { R: 5'-CAATTACAGGGCCTCGAAAG-3' }\end{array}$ \\
\hline Caspase- 3 & $\begin{array}{l}\text { F: 5'-AGAGCTGGACTGCGGTATTGG } \\
\text { AG-3' } \\
\text { R: 5'-GAACCATGACCCGTCCCTTG-3' }\end{array}$ \\
\hline Cytochrome $c$ & $\begin{array}{l}\text { F: 5'-CTTACACAGCCGCCAATA-3' } \\
\text { R: 5'-CTTCTTCTTAATGCCGACAA-3' }\end{array}$ \\
\hline GRP78 & $\begin{array}{l}\text { F: 5'-CCTGGTACTGCTTGATGTAT-3' } \\
\text { R: 5'-TTCTGCTGTATCCTCTTCAC-3' }\end{array}$ \\
\hline $\mathrm{CHOP}$ & $\begin{array}{l}\text { F: 5'-CTTCATACATCACCACACCT-3' } \\
\text { R: 5'-GTAGTCAGTAGCCACTTCT-3' }\end{array}$ \\
\hline PERK & $\begin{array}{l}\text { F: 5'-TGTCGCCAATGGGATAGTGAC } \\
\text { GAA-3' } \\
\text { R: 5' AATCCGGCTCTCGTTTCCATGT } \\
\text { CT-3' }\end{array}$ \\
\hline ATF4 & $\begin{array}{l}\text { F: 5'-CTGACCACGTTGGATGACAC-3' } \\
\text { R: 5'-GGGCTCATACAGATGCCTCT-3' }\end{array}$ \\
\hline Beclin-1 & $\begin{array}{l}\text { F: 5'-GAGTTTCAAGATCCTGGACCGT } \\
\text { GTCA-3' } \\
\text { R: 5'-CTGTTGGCACTTTCTGTGGACA } \\
\text { TCA-3' }\end{array}$ \\
\hline AMPK & $\begin{array}{l}\text { F: 5'-AAACCCACAGAAATCCAAACAC-3' } \\
\text { R: 5'-CCTTCCATTCATAGTCCAACTG-3' }\end{array}$ \\
\hline ULK1 & $\begin{array}{l}\text { F: 5'-ACCGCATTCACAGCATCACT -3' } \\
\text { R: 5'-ACCGCATTCACAGCATCACT -3' }\end{array}$ \\
\hline mTOR & $\begin{array}{l}\text { F: 5'-CTGGGACTCAAATGTGTGCAGT } \\
\text { TC-3' } \\
\text { R: 5'-GAACAATAGGGTGAATGATCCG } \\
\text { GG-3' }\end{array}$ \\
\hline p62 & $\begin{array}{l}\text { F: 5'-GGCCGCCCTGTTCCCCG-3' } \\
\text { R: 5'-GCCGGCACTCTTTTTTCTCTT-3' }\end{array}$ \\
\hline
\end{tabular}

AMPK, AMP-activated protein kinase; F, forward; R, reverse.

Rapa for $24 \mathrm{~h}$. Then the cells were washed twice with ice-cold PBS, centrifuged at $600 \mathrm{x} \mathrm{g}$ for $5 \mathrm{~min}$. Subsequently, the cell pellets were resuspended in culture medium with $5 \mu \mathrm{mol} / 1$ Rhodamine- 123 and incubated at $37^{\circ} \mathrm{C}$ in the dark for $30 \mathrm{~min}$, and then washed and resuspended in culture medium. The mean fluorescence intensity of Rhodamine-123 was detected using a flow cytometer (FACSCalibur; BD Biosciences) at an excitation of $488 \mathrm{~nm}$ and an emission of $585 \mathrm{~nm}$.

Statistical analysis. Sample capacity for each experiment was adjusted according to the variance obtained. Data were expressed as the mean \pm SD. All statistics were calculated using the SPSS 17.0 software (SPSS, Inc., Chicago, IL, USA). All experiments described were performed at least in triplicate. The statistical significance of differences was analyzed by Student's t-test between two groups or one-way analysis of variance (ANOVA) followed by Dunnett's post hoc test for 
A

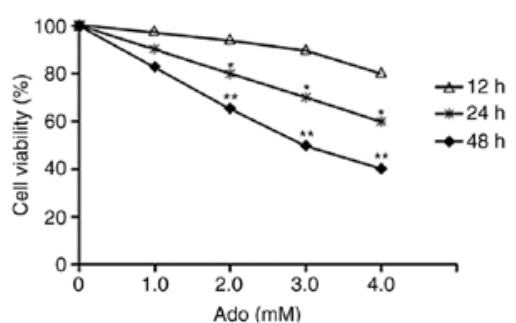

B
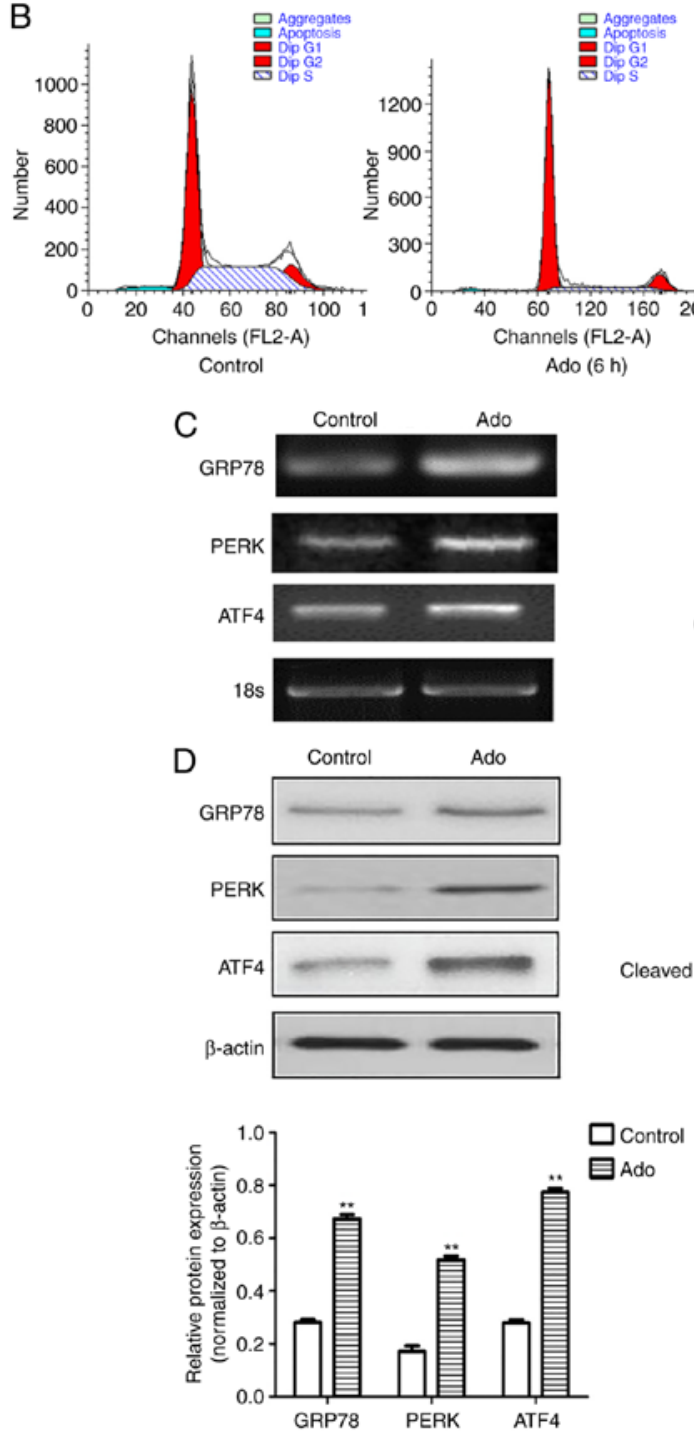
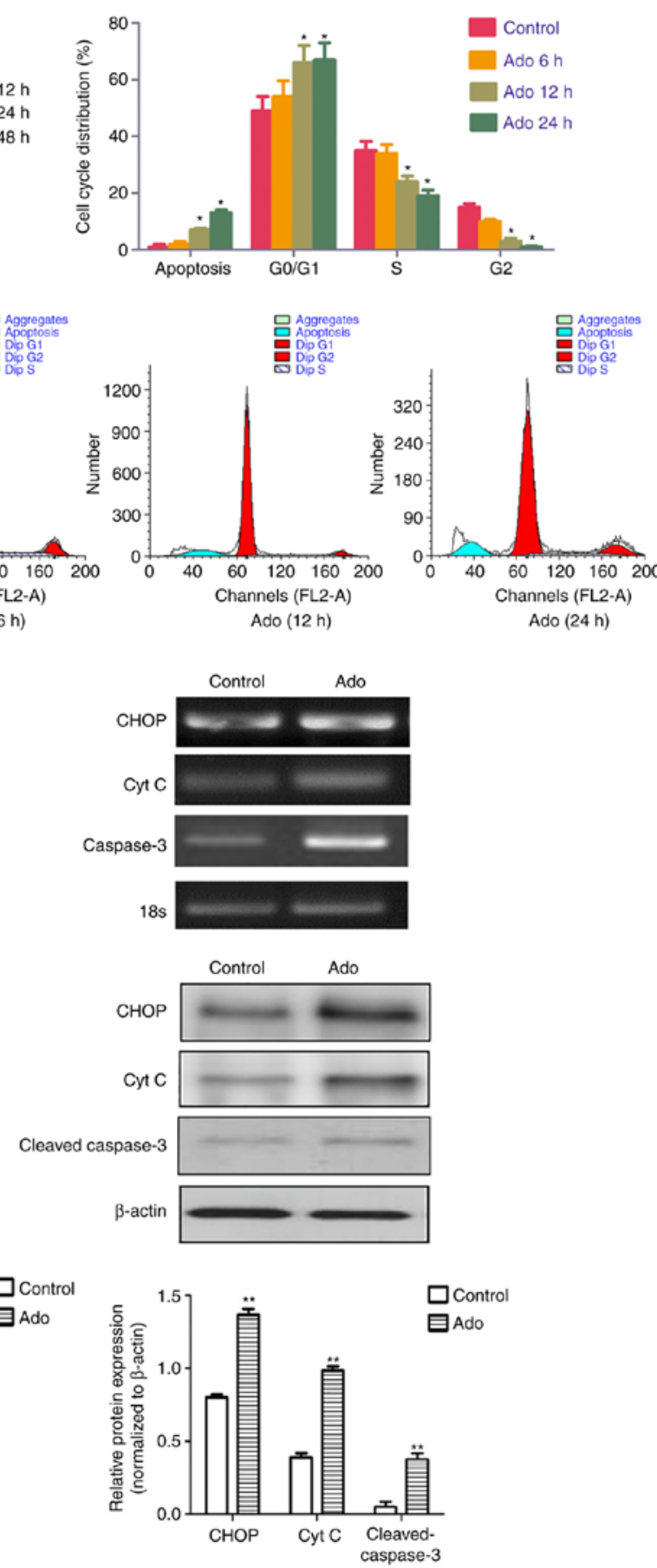

Figure 1. Ado inhibits cell viability and triggers ER stress in HepG2 cells. (A) Time- and dose-dependent cytotoxic effects of Ado on HepG2 cells. Cells were treated with different concentrations of Ado (1.0-4.0 mM) for 12,24, or $48 \mathrm{~h}$. Cell viability was determined by MTT assay. Results are expressed as percentages of cell growth relative to initial number of viable cells. (B) Cells were treated with $2.0 \mathrm{mM}$ for 6,12 , or $24 \mathrm{~h}$. The cell cycle distribution was evaluated using flow cytometric assay by PI staining. (C) HepG2 cells were treated with $2.0 \mathrm{mM}$ Ado for $24 \mathrm{~h}$. Cells were collected and subjected to total RNA extraction. The mRNA levels of ER stress-related genes GRP78, PERK, ATF4, CHOP, Cyt C and caspase-3 were assessed by RT-PCR. (D) HepG2 cells underwent the aforementioned treatment and were collected and subjected to western blot analyses with specific antibodies directed against GRP78, PERK, ATF4, CHOP, Cyt $\mathrm{C}$ and cleaved caspase-3, or $\beta$-actin. The density of the corresponding bands was assessed quantitatively using image analysis software and corrected by reference to the value of $\beta$-actin. Bar graphs represent the mean fluorescence intensity. ${ }^{*} \mathrm{P}<0.05,{ }^{* *} \mathrm{P}<0.01$ denotes significant difference from the normal control HepG2 cells; Ado, adenosine; ER, endoplasmic reticulum; Cyt C, cytochrome $c$; PI, propidium iodide.

multiple comparisons. $\mathrm{P}<0.05$ was considered to indicate a statistically significant difference.

\section{Results}

Ado inhibits cell viability, induces ER stress and GO/G1 cell cycle arrest. Cell viability was investigated using an MTT assay. HepG2 cells were treated with different concentrations of Ado (1.0-4.0 mM) for 12, 24 and $48 \mathrm{~h}$. As revealed in Fig. 1A, $1.0 \mathrm{mM}$ Ado did not significantly affect cell viability from 12 to $48 \mathrm{~h}$. However, Ado treatment at $2.0-4.0 \mathrm{mM}$ significantly decreased viability as time increased from 12 to $48 \mathrm{~h}$, revealing that Ado inhibited the growth of HepG2 cells in a time- and concentration-dependent manner. In addition, 
A

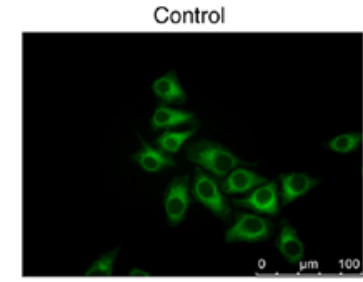

B
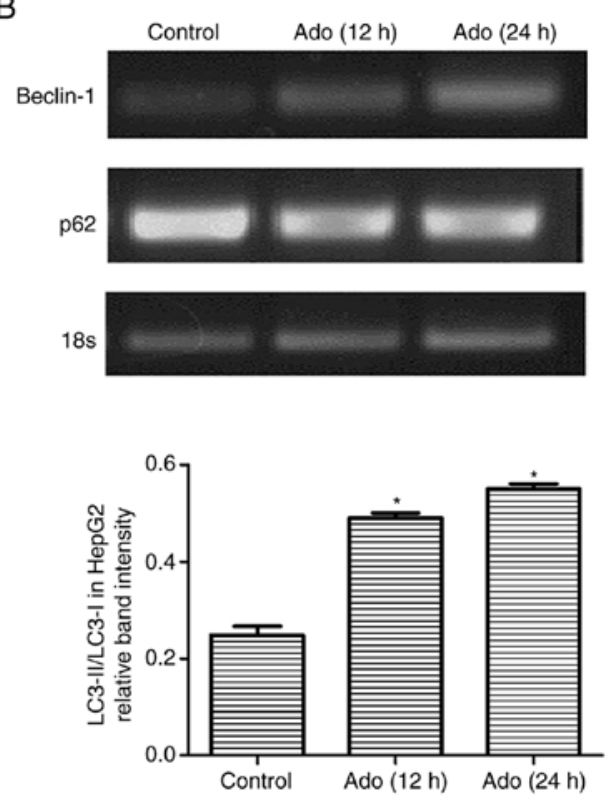

Ado (12 h)
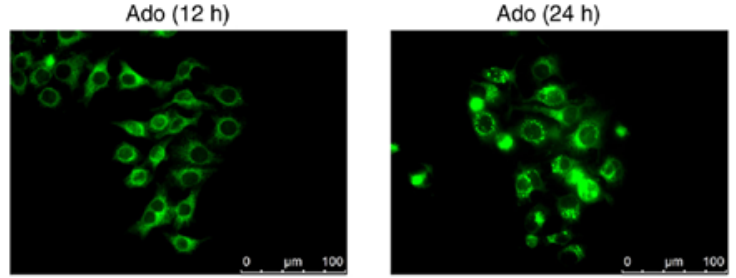

C
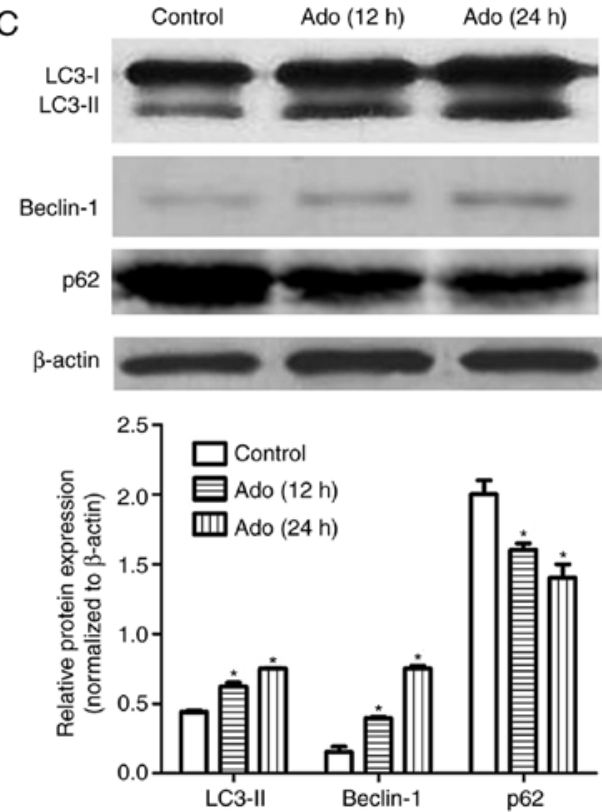

Figure 2. Ado induces autophagy in HepG2 cells. (A) HepG2 cells were treated with 2.0 mM for 12 , or 24 h and cells were stained with MDC. The autophagosomes were detected under fluorescence microscopy (magnification, x200). (B) The mRNA levels of autophagy-related genes Beclin-1 and p62 were assessed by RT-PCR. (C) HepG2 cells underwent the aforementioned treatment and were collected and subjected to western blot analyses with specific antibodies directed against LC3-I, LC3-II, Beclin-1, p62 or $\beta$-actin. Bar graphs represent the mean protein band intensity. Relative quantity of the aforementioned proteins was computed after normalization with $\beta$-actin. ${ }^{*} \mathrm{P}<0.05$ with the respect to the control. Ado, adenosine; MDC, monodansylcadaverine; LC3-II, microtubule-associated protein1 light chain 3-II.

Ado-induced suppression of viability was due to the arrest of cell cycle progression, which was confirmed by the flow cytometric assay. Our data demonstrated that Ado significantly increased the percentage of cells in the G0/G1 stage and decreased the percentage of cells in the $\mathrm{S}$ and $\mathrm{G} 2 / \mathrm{M}$ phases in HepG2 cells, compared with the control (Fig. 1B). Statistical results revealed that Ado also increased the percentage of sub-G1 phase (an apoptotic peak), which was consistent with our results by fluorescence microscopy observation and Annexin V/PI assay (Figs. 3B and 4A).

The endoplasmic reticulum (ER) is a highly dynamic organelle in eukaryotic cells. Many studies have indicated that once UPRs (PERK, ATF6 and/or IRE1) are activated, they initiate an early adaptive response to inhibit transcription and translation, and to increase the expression of GRP78 $(4,19)$. However, with prolonged stress, additional responses are initiated, including caspase-12/-9/-3 and ERK/ATF4/CHOP, which can promote cell apoptosis (25). In our previous study, it was demonstrated that the caspase-12/-9/-3 pathway played an important role in Ado-mediated apoptosis (19). To investigate whether other ER stress pathways following Ado treatment were activated in HepG2 cells, RT-PCR and western blot analyses were performed to detect the expression of GRP78, PERK, ATF4, CHOP, Cyt C and cleaved caspase-3. The results revealed that the mRNA and protein expression levels of the aforementioned relative genes were significantly increased after Ado treatment, indicating that the ATF4/CHOP pathway also participated in Ado-induced apoptosis (Fig. 1C and D), which enriched our understanding of Ado-induced apoptosis through ER stress in HepG2 cells. Collectively, these data indicated that the effect of Ado on the inhibition of cell growth was associated with G0/G1 cell cycle arrest and ER stress-related apoptosis.

Ado induces autophagy in HepG2 cells. In the present study, three different methods were applied to explore autophagic flux. Firstly, fluorescence microscopic evaluation revealed an increased amount of autophagosomes in the cells treated with Ado from 12 to $24 \mathrm{~h}$ (Fig. 2A). Secondly, we assessed the expression of autophagy-related proteins, Beclin-1 and p62. Beclin-1 is an initiative regulator of autophagy and p62 is a marker of autophagosome degradation. p62 decreases when autophagy is triggered and accumulates when autophagy is inhibited. The results demonstrated that Ado significantly reduced p62 levels in a time-dependent manner. Conversely, Ado increased Beclin-1 and LC3-II expression (Fig. 2B and C). Thirdly, the expression of LC3-II and the ratio of LC3-II/LC3-I was significantly increased after Ado treatment in HepG2 cells (Fig. 2C). Collectively, all these data demonstrated that Ado induced autophagy in HepG2 cells. 
A

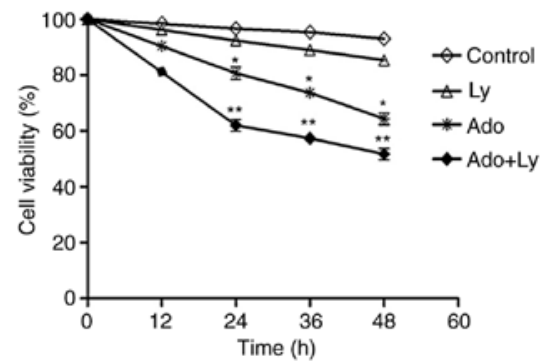

B
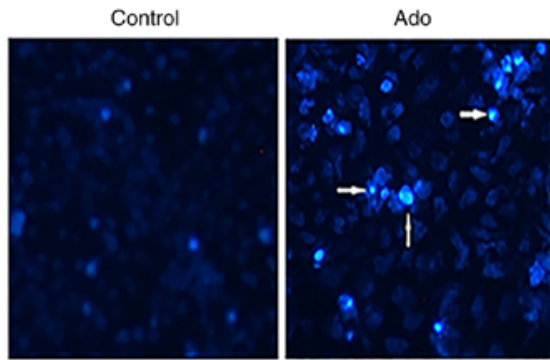

C

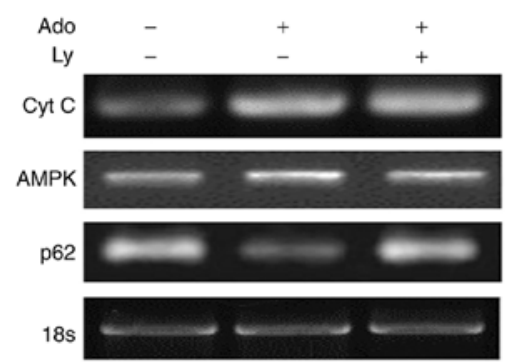

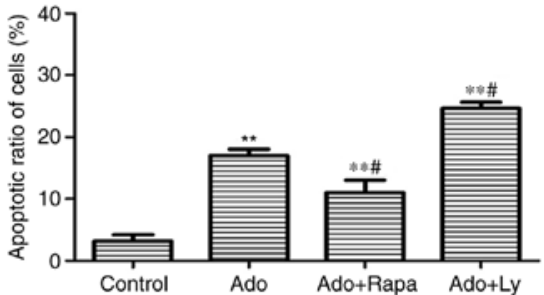

Ado+Rapa
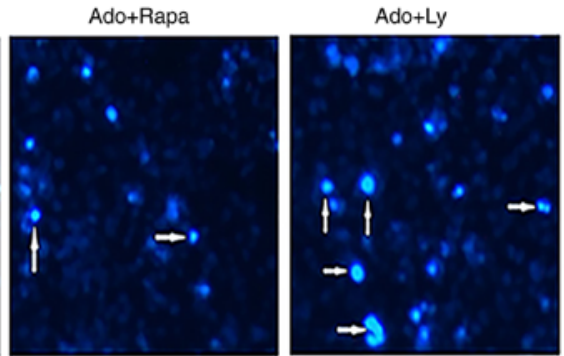

D Ado

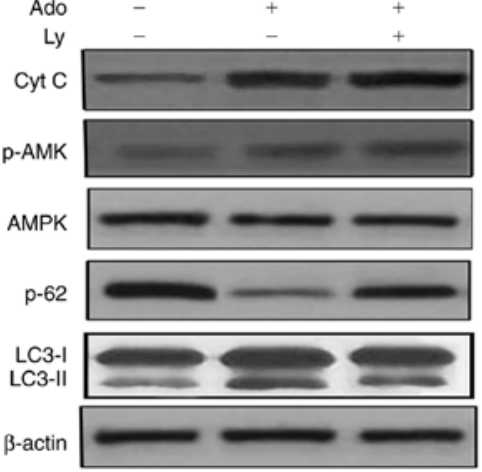

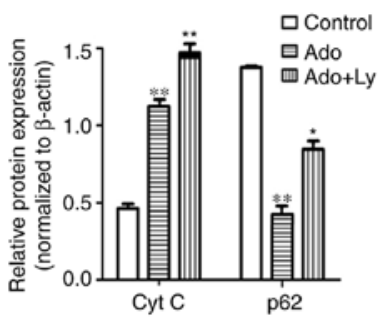
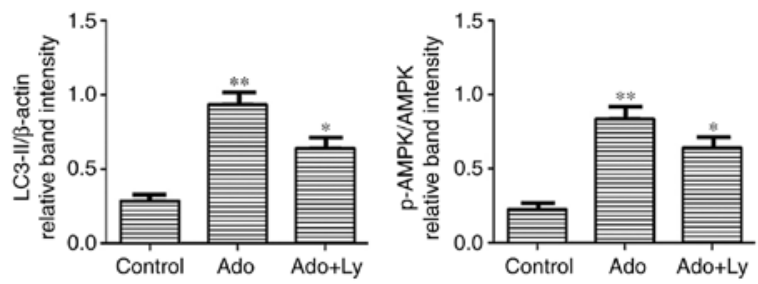

E
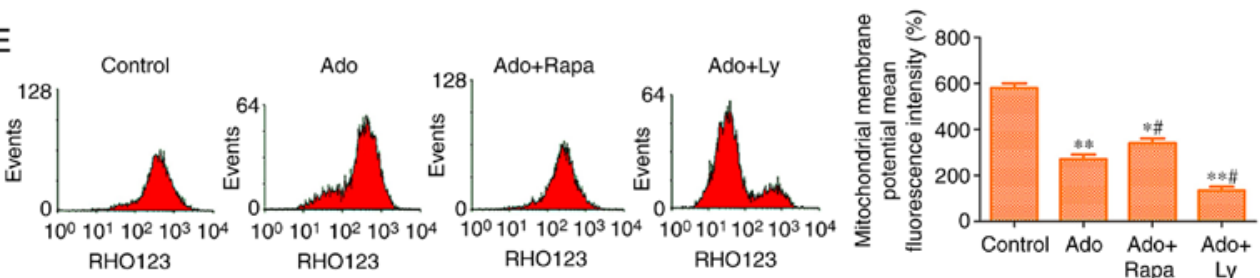

Figure 3. Inhibition of autophagy enhances ER stress-mediated apoptotic cell death. (A) HepG2 cells were treated with 2.0 mM Ado or $10 \mu \mathrm{M}$ LY alone. In the combination treatment group, the cells were pre-treated with $10 \mu \mathrm{M} \mathrm{LY}$ for $2 \mathrm{~h}$, followed by $2.0 \mathrm{mM}$ Ado treatment. Cell viability was determined by MTT assay at the indicated time-points. (B) Cell apoptosis was detected by Hoechst staining. Images were captured under a fluorescence microscope (original magnification, x200). Arrows indicate apoptotic cells. (C) The mRNA levels of Cyt C, AMPK and p62 were assessed by RT-PCR. (D) HepG2 cells underwent the aforementioned treatment and were collected and subjected to western blot analyses with specific antibodies directed against Cyt $\mathrm{C}$, p-AMPK, AMPK, p62, LC3-I and LC3-II, or $\beta$-actin. Bar graphs represent the mean protein band intensity. Relative quantity of the aforementioned proteins was computed. (E) Mitochondrial membrane potential $(\Delta \Psi \mathrm{m})$ indicated by Rhodamine-123 was detected by flow cytometry. Bar graphs represent the mean fluorescence intensity. ${ }^{*} \mathrm{P}<0.05,{ }^{* *} \mathrm{P}<0.01$ vs. the control; ${ }^{*} \mathrm{P}<0.05$ vs. the Ado group. ER, endoplasmic reticulum; Ado, adenosine; Cyt $\mathrm{C}$, cytochrome $c$; AMPK, AMP-activated protein kinase; LC3-II, microtubule-associated protein1 light chain 3-II.

Ado induces cell apoptosis and LY enhances Ado-induced apoptosis. Since cell growth inhibition is always associated with cell apoptosis, we further detected whether Ado induced apoptosis by Hoechst staining. Following Ado treatment for
$24 \mathrm{~h}$, cell nuclei became condensed and shrunk. In addition, typical apoptotic bodies appeared and the cell apoptotic ratio increased (Fig. 3B). Apoptotic cell death, besides characteristics such as chromatin condensation and apoptotic body 
formation, was also accompanied by typical mitochondrial changes. The latter includes enhanced membrane permeability, a decrease in mitochondrial membrane potential $(\Delta \Psi \mathrm{m})$ and release of cytochrome $c$ into the cytosol. To investigate the role of Ado-induced autophagy on apoptosis in HepG2 cells, cells were pretreated with autophagy inhibitor LY294002 (LY, $10 \mu \mathrm{M}$ ) or autophagy activator rapamycin (Rapa, $20 \mu \mathrm{M}$ ) for $1 \mathrm{~h}$, followed by treatment with Ado for an additional $24 \mathrm{~h}$. As revealed in Fig. 3A, $10 \mu \mathrm{M}$ LY only slightly reduced the viability of HepG2 cells at different time-points, but there was no significant difference when compared with the control group. However, $2.0 \mathrm{mM}$ Ado in combination with $10 \mu \mathrm{M} \mathrm{LY}$ significantly reduced the viability with the increase of time from 24 to $48 \mathrm{~h}$. Furthermore, the pharmacological inhibition of autophagy by LY significantly increased the mRNA and protein expression levels of cytochrome $c$ and p62, decreased the expression level of LC3-II, and enhanced the loss of the $\Delta \Psi \mathrm{m}$. Conversely, combination treatment of Ado with Rapa, significantly increased the $\Delta \Psi \mathrm{m}$ and decreased the number of apoptotic cells, compared with the Ado alone group (Fig. 3B and E). These results revealed that the inhibition of autophagy increased Ado-induced cytotoxic effects and the activation of autophagy alleviated Ado-induced apoptosis, indicating that autophagy plays a protective role in Ado-induced apoptosis in HepG2 cells.

Ado induces autophagy by activating AMPK and downregulating the mTOR signaling pathway. As aforementioned, it was determined that HepG2 cells treated with Ado exhibited increased apoptosis and autophagy. It is well-known that the AMPK/mTOR pathway functions as an autophagy regulator under starvation or other cellular stress conditions (26). Ado may increase the ratio of AMP/ATP in cells and thus lead to the activation of AMPK, which may promote autophagosome formation (27). In the present study, RT-PCR and western blot analysis demonstrated that Ado increased the mRNA and phosphorylated protein expression of AMPK (Figs. 3D and 4B). Therefore, the possible role of the AMPK-mediated autophagy signaling pathway was further investigated. The AMPK-siRNA plasmids were used to achieve a specific knockdown of AMPK in HepG2 cells. Ado increased the ratio of $\mathrm{p}$-AMPK/AMPK, $\mathrm{p}-\mathrm{ULK} 1 / \mathrm{ULK} 1$, and decreased the ratio of $\mathrm{p}-\mathrm{mTOR} / \mathrm{mTOR}$ and $\mathrm{p} 62$ expression level. Knockdown of AMPK abrogated Ado-induced activation of p-ULK1 and mTOR inhibition, increased p62 expression and the cell apoptosis ratio (Fig. 4A-C). Furthermore, we observed that knockdown of AMPK significantly increased ER stress-related apoptosis as evidenced by increased induction of CHOP, cleaved caspase-3, Cyt C (Fig. 4C) and the loss of mitochondrial membrane potential ( $\Delta \Psi \mathrm{m})$ (Fig. 4D). Collectively, in HepG2 cell lines, Ado-induced AMPK/mTOR pathway activation partially blocked ER stress and decreased apoptotic cell death.

\section{Discussion}

Ado is a common metabolite of ATP, which exhibits cytotoxic effects at high concentrations. Numerous in vitro experiments have demonstrated that Ado can induce apoptotic cell death in various types of cancer cells via several mechanisms, including promotion of cell cycle arrest, apoptosis and suppression of signal transduction (15-17). However, the mechanisms underlying the cytotoxic effects of Ado are not totally understood. It was demonstrated that ER stress was involved in Ado-induced apoptosis in a previous study (19). In the early stage of ER stress, UPR plays an important role to maintain cell homeostasis and there is cross-talk between UPR and autophagy (18). We hypothesized that autophagy probably participated in this process. In the present study, we demonstrated that Ado induced both apoptosis and autophagy concurrently in HepG2 cells. The main mechanism of autophagy was found to be via AMPK activation of intracellular energy sensor and subsequent inhibition of the main autophagy suppressor mTOR (Fig. 4).

Clinically, it has been suggested that the cell cycle is a primary target for cancer treatment (28). In the present study, Ado was observed to cause a time- and concentration-dependent inhibition of cell proliferation in HepG2 cells (Fig. 1A). The results of cell cycle analysis revealed that Ado arrested cells in the G0/G1 phase and prevented them from transitioning to the S phase (Fig. 1B). G0 is the resting phase in which cells stop dividing and leave the cell cycle, while cells prepare energy and material for DNA replication in the G1 phase (29). Therefore, arrest of cells in the G0/G1 phase results in the obstruction of mitosis and cellular DNA synthesis. Thus, Ado-induced proliferation inhibition was related to cell cycle arrest in HepG2 cells.

Cell apoptosis is a programmed cell death process triggered. There are three different pathways, including the cell death receptor apoptotic pathway, ER stress and the mitochondrial apoptotic pathway (30). The ER stress apoptotic pathway involves UPR and loss of $\Delta \Psi \mathrm{m}$ and the subsequent release of cytochrome $c$ from mitochondria to the cytoplasm $(21,22)$. In the present study, Hoechst staining revealed that Ado treatment caused obvious nuclear condensation, which is a typical characteristic of apoptosis (Fig. 3B). Flow cytometric assessment of Annexin V/PI staining further confirmed that Ado increased the proportion of apoptotic cells (Fig. 4A). The results of RT-PCR and western blotting demonstrated that Ado significantly increased the mRNA and protein expressions of GRP78, PERK, ATF4, CHOP, cleaved caspase-3 and cytochrome $c$ (Fig. 1C and D). Concurrently, Ado also caused the loss of $\Delta \Psi \mathrm{m}$ (Fig. 3E), revealing that Ado treatment impaired the mitochondria and caused the aberrant release of cytochrome $c$ from mitochondria into cytoplasm. Collectively, these findings indicated that Ado induced ER-related apoptosis in HepG2 cells.

Autophagy is a dynamic process comprised of two consecutive stages. The first step is autophagosome formation. The second step is autophagosome clearance, which involves autolysosome formation via autophagosome-lysosome fusion (31). Inhibiting autophagic flux can sensitize cells to stimulus-induced damage and cell death (3-5). In the present study, in addition to the induction of apoptosis, we also determined for the first time that Ado induced autophagy in HepG2 cells, as demonstrated by the increased autophagic vacuoles (Fig. 2A), accompanied with the increased levels of Beclin-1, the conversion of the molecular form of LC3 (LC3-I) to LC3-II, and the decreased expression of p62 (Fig. 2B and C). These are commonly used as markers for detecting autophagy (32). 
A
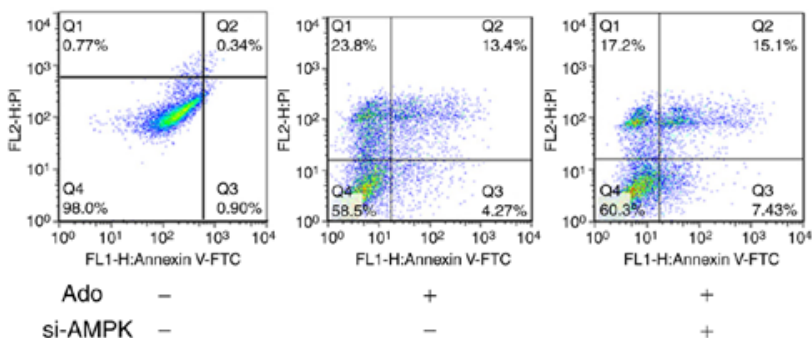

Si-AMPK -
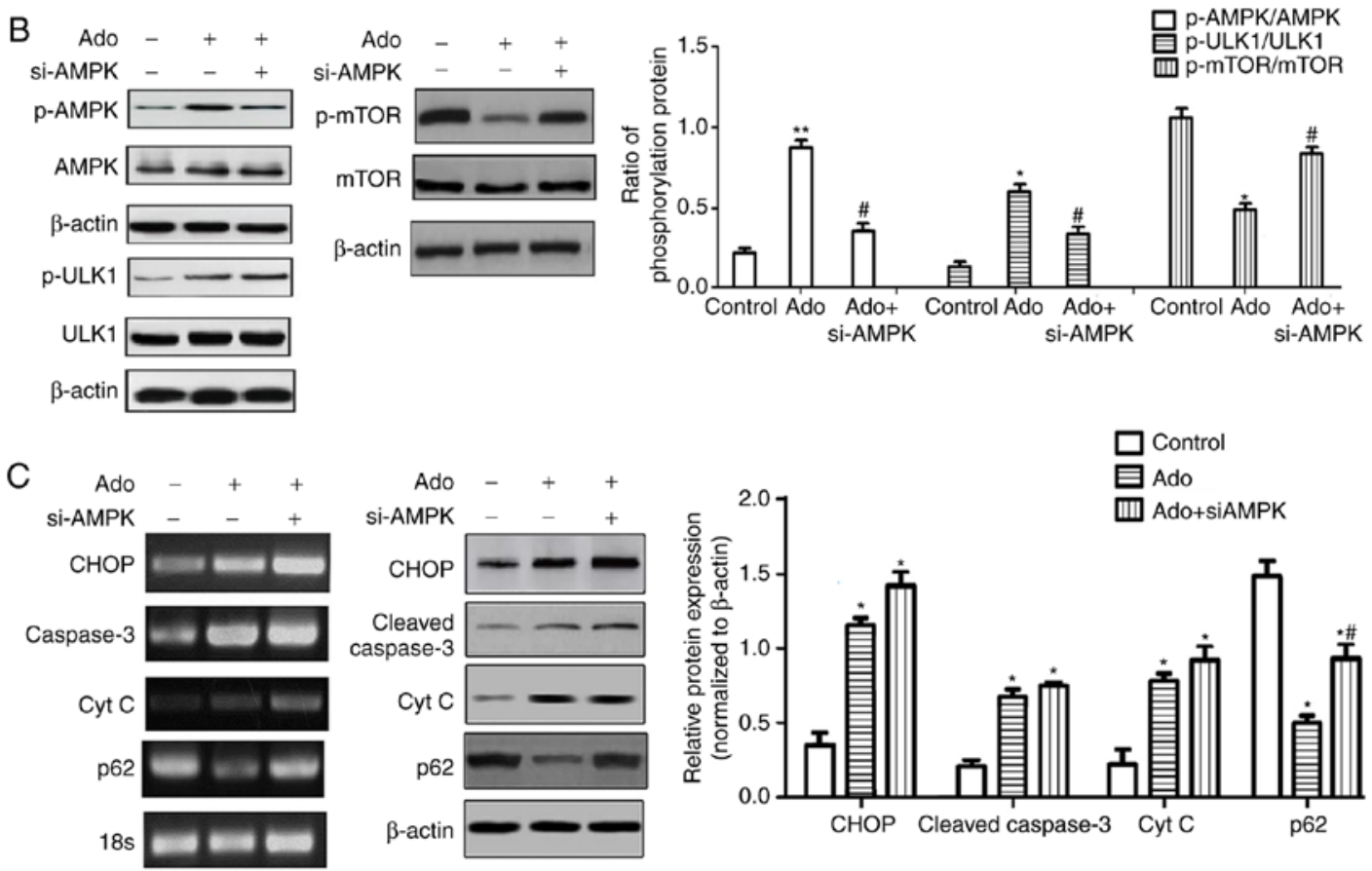

\section{$\mathrm{D}$}

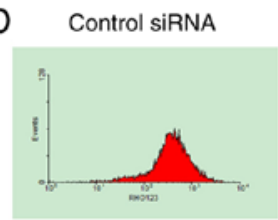

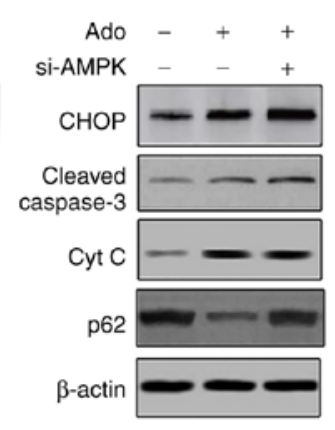

Ado

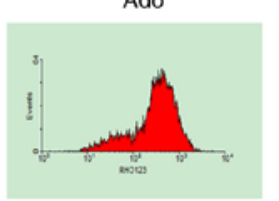

Ado+si-AMPK
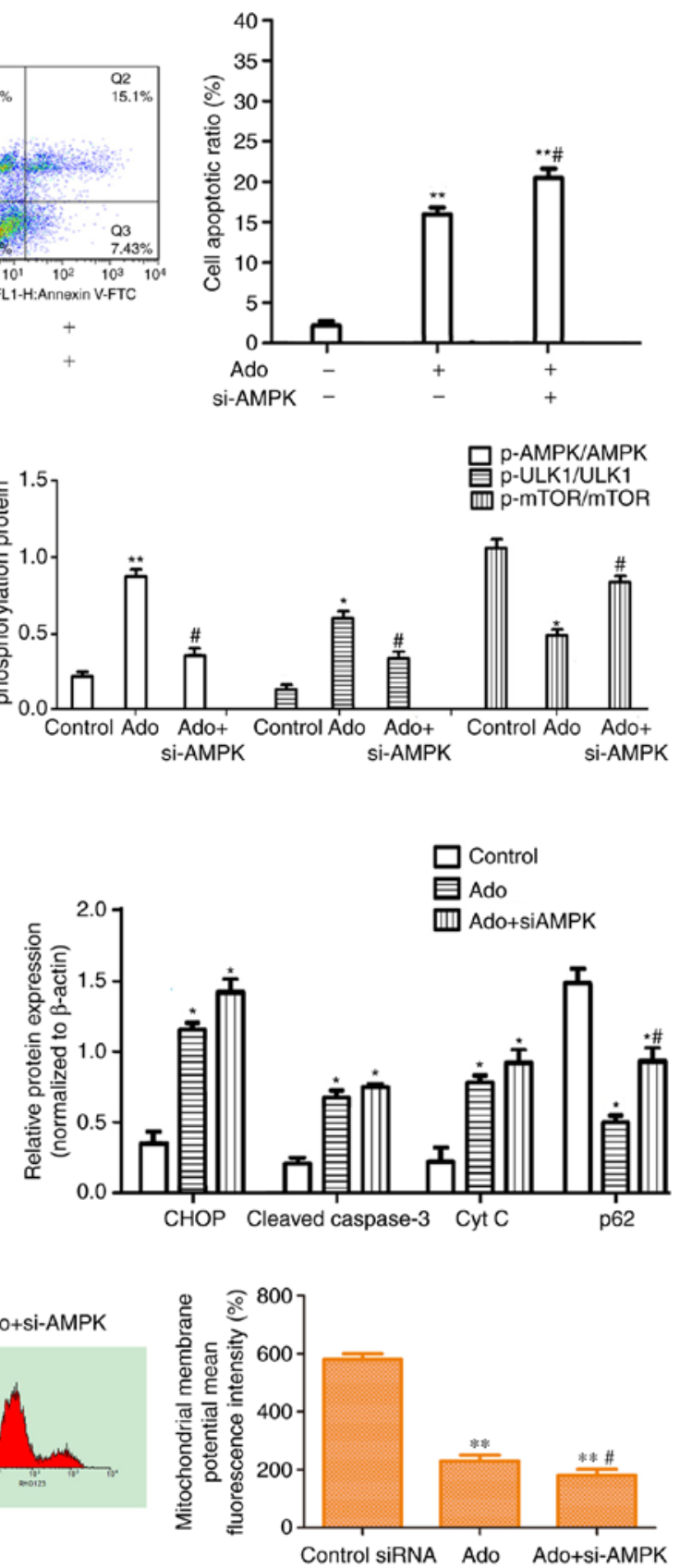

Figure 4. Inhibition of autophagy by AMPK siRNA enhances Ado-induced apoptosis and inhibits the AMPK/mTOR/ULK1 pathway. (A) HepG2 cells were transfected with AMPK siRNA $(20 \mu \mathrm{M})$ or control siRNA (transfected with empty vector, $20 \mu \mathrm{M}$ ), then exposed to $2.0 \mathrm{mM}$ Ado or not for $24 \mathrm{~h}$ and then the cell apoptotic ratio was determined by flow cytometry (FACS) with Annexin V-FITC and PI double staining. (B) HepG2 cells underwent the aforementioned treatment and were collected and the protein levels of the AMPK/mTOR/ULK1 pathway were assessed by western blotting. The phosphorylation ratios of p-AMPK/AMPK, p-ULK1/ULK1 and p-mTOR/mTOR were computed (C) The mRNA and protein levels of ER stress-related genes were assessed by RT-PCR and western blotting. HepG2 cells underwent the aforementioned treatment and were collected and subjected to western blot analyses with specific antibodies directed against CHOP, cleaved caspase-3, p62 and Cyt C or $\beta$-actin. Bar graphs represent the mean protein band intensity. (D) Mitochondrial membrane potential $(\Delta \Psi \mathrm{m})$ indicated by Rhodamine-123 was detected by flow cytometry. Bar graphs represent the mean fluorescence intensity. ${ }^{*} \mathrm{P}<0.05$, ${ }^{* *} \mathrm{P}<0.01$ vs. control; ${ }^{\sharp} \mathrm{P}<0.05$ vs. Ado group. Ado, adenosine; AMPK, AMP-activated protein kinase; PI, propidium iodide; ER, endoplasmic reticulum.

Both apoptosis and autophagy are important in normal physiology and in a wide range of diseases and cross-talk also occurs between them. Studies have revealed that after treatment with antitumor drugs, some cancer cells undergo autophagy as a temporary survival mechanism, and the suppression of autophagy leads to apoptosis and enhances antitumor effects (3). However, some treatments also result in the induction of autophagic cell death or both apoptosis and autophagy (12). To further investigate the interplay between autophagy and apoptotic death, HepG2 cells were pretreated with autophagy inhibitors (LY) or an autophagy inducer (Rapa). LY has been revealed to inactivate $\mathrm{Akt} / \mathrm{PKB}$, decrease the expression of phosphorylated Akt (Ser473), inhibit cancer cell growth and induce apoptosis. LY has also been revealed to act on HepG2 cells, induce significant nuclear pyknosis and reduce cytoplasmic volume (33). However, the anticancer effect of LY is closely related to its concentration. As revealed in Fig. 3A, $10 \mu \mathrm{M}$ LY only slightly reduced the viability of 
HepG2 cells at different time-points. When the dose of LY increased to $30 \mu \mathrm{M}$, MTT assays revealed that after 12, 24, 36 and $48 \mathrm{~h}$ of treatment, the rates of viability were $91.41 \pm 9.33$, $83.82 \pm 9.14,75.14 \pm 8.14$ and $64.71 \pm 6.78 \%$, respectively (data not shown). The viability of HepG2 cells significantly decreased, compared with the control group $(\mathrm{P}<0.05)$. This was in line with a previous study (34). Thus, the dose of $10 \mu \mathrm{M} \mathrm{LY}$, which did not significantly affect the viability of HepG2 cells, was used in subsequent experiments in order to observe the cytotoxic effect of Ado and the role of inhibition of autophagy. The results revealed that $\mathrm{LY}$, the autophagy inhibitor, increased the expression level of p62 and decreased the expression level of LC3-II, enhancing Ado-induced apoptosis and proliferation inhibition in HepG2 cells (Fig. 3A-D). In contrast, pretreatment with Rapa significantly decreased the apoptotic ratio and increased the mitochondrial membrane potential (Fig. 3B and E). These results indicated that autophagy regulated Ado-induced apoptosis and played a protective role in HepG2 cells.

Cell autophagy is affected by AMPK phosphorylation and activity of Mtor (35). AMPK is a major regulator of cellular energy homeostasis, and it regulates carbohydrate and fat metabolism in order to maintain the cellular energy balance $(36,37)$. AMPK is activated by metabolic stressors that deplete ATP and increase AMP, and by upstream kinases that induce its phosphorylation at Thr172. Several avenues of evidence have pointed to Ado as an activator of AMPK by increasing intracellular AMP concentrations or by binding to the Ado receptors on the cell membrane $(38,39)$. The mechanism by which AMPK activates autophagic response presumably involves downregulation of mTOR and activation of ULK1 (40). As physiological stresses result in both AMPK activation and mTOR inhibition, ULK1 initiates the autophagy process (41). In the present study, our results demonstrated that Ado activated the AMPK/mTOR/ULK1 pathway, as evidenced by the increased ratio of $\mathrm{p}-\mathrm{AMPK} / \mathrm{AMPK}, \mathrm{p}-\mathrm{ULK} 1 / \mathrm{ULK} 1$ and the decreased ratio of $\mathrm{p}$-mTOR/mTOR. Knockdown of AMPK by si-AMPK abolished Ado-induced mTOR inhibition and ULK1 activation, thereby downregulating autophagy, which was ascertained by the increased p62 expression (Fig. 4C). These data revealed that Ado activated AMPK and triggered autophagy in a double-pronged mechanism of directly activating ULK1 and inhibiting mTOR protein expression, which was consistent with the increased autophagy (Fig. 2A-C). Concurrently, we also observed that knockdown of AMPK further enhanced CHOP pathway activation, as evidenced by increased expression levels of CHOP, cleaved caspase-3, the cell apoptosis ratio and decreased mitochondrial membrane potential $(\Delta \Psi \mathrm{m})$ (Fig. 4A, C and D). These results indicated that the AMPK/mTOR/ULK1 pathway was involved in Ado-induced autophagy and autophagy played a protective effect in Ado-induced apoptosis. Therefore, our study demonstrated that AMPK may act as an important factor governing the cross talk between apoptosis and autophagy in HepG2 cells. Whether Ado alters the ratio of intracellular AMP/ATP or directly activates its receptors on the cell membrane and leads to AMPK activation remains to be further explored.

In conclusion, our present study revealed that Ado-induced ER stress resulted in apoptosis and autophagy concurrently. Autophagy may regulate Ado-induced cytotoxicity via the activation of the AMPK/mTOR/ULK1 signaling pathway and autophagy may play a protective role in the apoptotic process. Inhibition of autophagy may effectively enhance the anticancer effect of Ado in human hepatoblastoma HepG2 cells.

\section{Acknowledgements}

Not applicable.

\section{Funding}

The present study was supported by the Guangdong Natural Science Foundation in China (no. 2014A030313470) and the Guangdong Science and Technology Planning Project (no. 2014A020212284). This study was also supported by the Department of Education, Guangdong Government under the Top-tier University Development Scheme for Research and Control of Infectious Diseases.

\section{Availability of data and materials}

The datasets generated/analyzed during the present study are available from the corresponding author on reasonable request.

\section{Authors' contributions}

LFW designed and wrote the study. HCZ contributed significantly to the data analysis and the manuscript preparation. XTZ, ZJP, LXL and GPL performed the experiments and wrote the manuscript. JLF analyzed the data and approved the final version of the manuscript. All authors read and approved the manuscript and agree to be accountable for all aspects of the research in ensuring that the accuracy or integrity of any part of the work are appropriately investigated and resolved.

\section{Ethics approval and consent to participate}

Not applicable.

\section{Patient consent for publication}

Not applicable.

\section{Competing interests}

The authors declare that they have no competing interests.

\section{References}

1. Mokdad AA, Singal AG and Yopp AC: Advances in local and systemic therapies for hepatocellular cancer. Curr Oncol Rep 18: 9, 2016.

2. Lin J, Wu L, Bai X, Xie Y, Wang A, Zhang H, Yang X, Wan X, Lu X, Sang X, et al: Combination treatment including targeted therapy for advanced hepatocellular carcinoma. Oncotarget 7: 71036-71051, 2016.

3. Zhou J, Li G, Zheng Y, Shen HM, Hu X, Ming QL, Huang C, Li P and Gao N: A novel autophagy/mitophagy inhibitor liensinine sensitizes breast cancer cells to chemotherapy through DNM1L-mediated mitochondrial fission. Autophagy 11: 1259-1279, 2015

4. Xie WY, Zhou XD, Li Q, Chen LX and Ran DH: Acid-induced autophagy protects human lung cancer cells from apoptosis by activating ER stress. Exp Cell Res 339: 270-279, 2015. 
5. Chi KH, Wang YS, Huang YC, Chiang HC, Chi MS, Chi CH, Wang HE and Kao SJ: Simultaneous activation and inhibition of autophagy sensitizes cancer cells to chemotherapy. Oncotarget 7: 58075-58088, 2016.

6. Rubiolo JA, López-Alonso H, Martínez P, Millán A, Cagide E, Vieytes MR, Vega FV and Botana LM: Yessotoxin induces ER-stress followed by autophagic cell death in glioma cells mediated by mTOR and BNIP3. Cell Signal 26: 419-432, 2014.

7. Artero-Castro A,Perez-Alea M,Feliciano A,LealJA,GenestarM, Castellvi J, Peg V, Ramón Y Cajal S and Lleonart ME: Disruption of the ribosomal P complex leads to stress-induced autophagy. Autophagy 11: 1499-1519, 2015.

8. Netea-Maier RT, Klück V,Plantinga TS and Smit JW: Autophagy in thyroid cancer: Present knowledge and future perspectives. Front Endocrinol 6: 22, 2015

9. Kovaleva V, Mora R, Park YJ, Plass C, Chiramel AI, Bartenschlager R, Döhner H, Stilgenbauer S, Pscherer A, Lichter P, et al: miRNA-130a targets $A T G 2 B$ and DICER1 to inhibit autophagy and trigger killing of chronic lymphocytic leukemia cells. Cancer Res 72: 1763-1772, 2012.

10. Jing Z, Sui X, Yao J, Xie J, Jiang L, Zhou Y, Pan H and Han W: SKF-96365 activates cytoprotective autophagy to delay apoptosis in colorectal cancer cells through inhibition of the calcium/CaMKII $\gamma /$ AKT-mediated pathway. Cancer Lett 372 226-238, 2016.

11. Liu Y, Gong W, Yang ZY, Zhou XS, Gong C, Zhang TR, Wei X, Ma D, Ye F and Gao QL: Quercetin induces protective autophagy and apoptosis through ER stress via the p-STAT3/Bcl-2 axis in ovarian cancer. Apoptosis 22: 544-557, 2017.

12. Hu JL, Hu XL, Guo AY, Wang CJ, Wen YY and Cang SD Endoplasmic reticulum stress promotes autophagy and apoptosis and reverses chemoresistance in human ovarian cancer cells Oncotarget 8: 49380-49394, 2017.

13. Sui X, Kong N, Ye L, Han W, Zhou J, Zhang Q, He C and Pan H: p38 and JNK MAPK pathways control the balance of apoptosis and autophagy in response to chemotherapeutic agents. Cancer Lett 344: 174-179, 2014.

14. Guo XL, Hu F, Zhang SS, Zhao QD, Zong C, Ye F, Guo SW Zhang JW, Li R, Wu MC, et al: Inhibition of p53 increases chemosensitivity to 5-FU in nutrient-deprived hepatocarcinoma cells by suppressing autophagy. Cancer Lett 346: 278-284, 2014.

15. Liu LX, Deng W, Zhou XT, Chen RP, Xiang MQ, Guo YT, Pu ZJ, Li R, Wang GF and Wu LF: The mechanism of adenosine-mediated activation of lncRNA MEG3 and its antitumor effects in human hepatoma cells. Int J Oncol 48: 421-429, 2016.

16. Hajiahmadi S, Panjehpour M, Aghaei M and Shabani M: Activation of $\mathrm{A} 2 \mathrm{~b}$ adenosine receptor regulates ovarian cancer cell growth: Involvement of $\mathrm{Bax} / \mathrm{Bcl}-2$ and caspase-3. Biochem Cell Biol 93: 321-319, 2015.

17. Yu S, Hou D, Chen P, Zhang Q, Lv B, Ma Y, Liu F, Liu H, Song EJ, Yang D, et al: Adenosine induces apoptosis through TNFR1/RIPK1/P38 axis in colon cancer cells. Biochem Biophys Res Commun 460: 759-765, 2015.

18. Hirsch C, Gauss R, Horn SC, Neuber O and Sommer T: The ubiquitylation machinery of the endoplasmic reticulum. Nature 458 : 453-460, 2009

19. Wu LF, Guo YT, Zhang QH, Xiang MQ, Deng W, Ye YQ, $\mathrm{Pu} \mathrm{ZJ}$, Feng JL and Huang GY: Enhanced antitumor effects of adenoviral-mediated siRNA against GRP78 gene on adenosine-induced apoptosis in human hepatoma HepG2 cells. Int J Mol Sci 15: 525-544, 2014.

20. Yasuda Y, Saito M, Yamamura T, Yaguchi T and Nishizaki T: Extracellular adenosine induces apoptosis in Caco-2 human colonic cancer cells by activating caspase- $9 /-3$ via $\mathrm{A}_{2 \mathrm{a}}$ adenosine receptors. J Gastroenterol 44: 56-65, 2009.

21. Gorman AM, Healy SJ, Jäger R and Samali A: Stress management at the ER: Regulators of ER stress-induced apoptosis. Pharmacol Ther 134: 306-316, 2012.

22. Zhang J, Singh N, Robinson-Taylor KS, Dorsett-Martin WA, Morris MW Jr, Earl TM and Anderson CD: Hepatocyte autophagy is linked to $\mathrm{C} / \mathrm{EBP}$-homologous protein, $\mathrm{Bcl} 2$-interacting mediator of cell death, and BH3-interacting domain death agonist gene expression. J Surg Res 195: 588-595, 2015.

23. Wu LF, Wei BL, Guo YT, Ye YQ, Li GP, Pu ZJ and Feng JL: Apoptosis induced by adenosine involves endoplasmic reticulum stress in EC109 cells. Int J Mol Med 30: 797-804, 2012.
24. Livak KJ and Schmittgen TD: Analysis of relative gene expression data using real-time quantitative PCR and the $2^{-\Delta \Delta C \mathrm{~T}}$ method. Methods 25: 402-408, 2001.

25. Bromati CR, Lellis-Santos C, Yamanaka TS, Nogueira TC, Leonelli M, Caperuto LC, Gorjão R, Leite AR, Anhê GF and Bordin S: UPR induces transient burst of apoptosis in islets of early lactating rats through reduced AKT phosphorylation via ATF4/CHOP stimulation of TRB3 expression. Am J Physiol Regul Integr Comp Physiol 300: R92-R100, 2011.

26. Varshney R, Varshney R, Mishra R, Gupta S, Sircar D and Roy P: Kaempferol alleviates palmitic acid-induced lipid stores, endoplasmic reticulum stress and pancreatic $\beta$-cell dysfunction through AMPK/mTOR-mediated lipophagy. J Nutr Biochem 57: 212-227, 2018.

27. Imamura K, Ogura T, Kishimoto A, Kaminishi M and Esumi H: Cellcycle regulation via 53 phosphorylation by a 5'-AMPactivated protein kinase activator, 5-aminoimidazole-4-carboxamide1-beta-D-ribofuranoside, in a human hepatocellular carcinoma cell line. Biochem Biophys Res Commun 287: 562-567, 2001

28. Oura K, Tadokoro T, Fujihara S, Morishita A, Chiyo T, Samukawa E, Yamana Y, Fujita K, Sakamoto T, Nomura T, et al: Telmisartan inhibits hepatocellular carcinoma cell proliferation control by inducing cell cycle arrest. Oncol Rep 38: 2825-2835, 2017.

29. Kang S, Kang MS, Ryu E and Myung K: Eukaryotic DNA replication: Orchestrated action of multi-subunit protein complexes. Mutat Res 809: 58-69, 2018.

30. Walter P and Ron D: The unfolded protein response: From stress pathway to homeostatic regulation. Science 334: 1081-1086, 2011.

31. Kenific CM and Debnath J: Cellular and metabolic functions for autophagy in cancer cells. Trends Cell Biol 25, 37-45, 2015.

32. Park JH, Lee JE, Shin IC and Koh HC: Autophagy regulates chlorpyrifos-induced apoptosis in SH-SY5Y cells. Toxicol Appl Pharmacol 268, 55-67, 2013.

33. Buontempo F, Ersahin T, Missiroli S, Senturk S, Etro D, Ozturk M, Capitani S, Cetin-Atalay R and Neri ML: Inhibition of Akt signaling in hepatoma cells induces apoptotic cell death independent of Akt activation status. Invest New Drugs 29: 1303-1313, 2011.

34. Xing CG, Zhu BS, Liu HH, Lin F, Yao HH, Liang ZQ and Qin ZH: LY294002 induces p53-dependent apoptosis of SGC7901 gastric cancer cells. Acta Pharmacol Sini 29: 489-498, 2008.

35. Hardie DG, Ross FA and Hawley SA: AMPK: A nutrient and energy sensor that maintains energy homeostasis. Nat Rev Mol Cell Biol 13: 251-262, 2012

36. Ojuka EO, Jones TE, Nolte LA, Chen M, Wamhoff BR, Sturek M and Holloszy JO: Regulation of GLUT4 biogenesis in muscle: Evidence for involvement of AMPK and $\mathrm{Ca}^{2+}$. Am J Physiol Endocrinol Metab 282: E1008-E1013, 2002.

37. Mihaylova MM and Shaw RJ: The AMPK signalling pathway coordinates cell growth and metabolism. Nat Cell Biol 13: 1016-1023, 2011

38. Galardo MN, Riera MF, Pellizzari EH, Sobarzo C, Scarcelli R, Denduchis B, Lustig L, Cigorraga SB and Meroni SB: Adenosine regulates Sertoli cell function by activating AMPK. Mol Cell Endocrinol 330: 49-58, 2010.

39. Aymerich I, Foufelle F, Ferré P, Casado FJ and Pastor-Anglada M: Extracellular adenosine activates AMP-dependent protein kinase (AMPK). J Cell Sci 119: 1612-1621, 2006.

40. Bolster DR, Crozier SJ, Kimball SR and Jefferson LS: AMP-activated protein kinase suppresses protein synthesis in rat skeletal muscle through down-regulated mammalian target of rapamycin (mTOR) signaling. J Biol Chem 277, 23977-23980, 2002.

41. Kim J, Kundu M, Viollet B and Guan KL: AMPK and mTOR regulate autophagy through direct phosphorylation of Ulk1. Nat Cell Biol 13: 132-141, 2011.

This work is licensed under a Creative Commons Attribution-NonCommercial-NoDerivatives 4.0 International (CC BY-NC-ND 4.0) License. 